\section{Walter Andreas Friedländer}

$1891-1984$
Am 20.9. jährt sich der Geburtstag Walter Andreas Friedländers zum 120. Mal. 1891 in Berlin geboren, wächst Friedländer in einem pazifistisch geprägten, jüdischen Elternhaus auf. Sein Onkel Hugo Haase, einer der führenden Sozialdemokraten der Kaiserzeit und der jungen Weimarer Republik, motiviert Friedländer nicht nur zum Jurastudium, sondern trägt auch zu dessen Politisierung bei: Friedländer tritt früh in die USPD ein und engagiert sich bereits als Student für eine grundlegende Reform des Jugendstrafrechts sowie der Fürsorgeerziehung. Dies wiederum bringt ihn in Kontakt mit Marie Juchacz, die den jungen Juristen und Parteirenegaten - Friedländer war zu diesem Zeitpunkt noch nicht in den Schoß der (M)SPD zurückgekehrt - bei der Gründung der Arbeiterwohlfahrt (AWO) in deren Beirat beruft. Sein politisches Engagement veranlasst Friedländer, die Rechtsanwaltstätigkeit zugunsten der Sozialen Arbeit aufzugeben: 1921 wird er zum hauptberuflichen Stadtrat in Berlin-Prenzlauer Berg gewählt und übernimmt dort die Leitung des Jugend- und des Wohlfahrtsamtes. Insbesondere bei der Ausgestaltung der Jugendhilfe im Problembezirk Prenzlauer Berg setzt Friedländer Meilensteine: Er errichtet eine allgemeinzuständige Familienfürsorge sowie Säuglingsfürsorgestellen, Krippen und Horte, entwickelt die stigmatisierende „Psychopathenfürsorge“ für seelisch Behinderte zu modernen Einrichtungen und Diensten der Heilerziehungspflege und baut wegweisende Einrichtungen der Jugendberufshilfe/Jugendsozialarbeit auf. Dabei wird Friedländer von namhaften Persönlichkeiten unterstützt: Zu seinem Team gehören u.a. die Malerin Käthe Kollwitz und deren Mann Karl im Jugendwohlfahrtsausschuss sowie die spätere Berliner Senatorin Ella Kay als Fürsorgerin; Alfred Adler, Siegfried Bernfeld und Otto Fenichel werden für die Fortbildung der JugendamtsmitarbeiterInnen gewonnen. Parallel dazu beginnt Friedländer, sich in der Ausbildung junger SozialarbeiterInnen und in der Fachdebatte der Sozialen Arbeit zu engagieren: Zwischen 1923 und 1933 hat er Lehraufträge am Sozialpädagogischen Seminar Berlin-Charlottenburg (Wohlfahrtsschule A. von Gierke), am Seminar für Jugendwohlfahrt (C. Mennicke), an der Wohlfahrtsschule der Arbeiterwohlfahrt (H. Wachenheim) und am Pestalozzi-Fröbel-Haus (A. Salomon). Daneben verfasst er zahlreiche Fachartikel zum Jugendwohlfahrtsrecht und zur Reform der Fürsorgeerziehung. Über seine Tätigkeit im AWO-Beirat und in den Fachkommissionen vernetzt sich Friedländer auch international und nimmt ab 1928 regelmäßig an den Internationalen Konferenzen für Sozialarbeit teil. Nach der Machtübernahme der Nationalsozialisten entgeht Friedländer nur durch Zufall einer Verhaftung durch die Gestapo; im März 1933 flieht er über Genf nach Zürich. Dort erhält er zwar Asyl und kann seine Familie zu sich holen, eine Berufstätigkeit ist ihm jedoch nicht gestattet. Im Sommer 1933 wechselt er deshalb nach Paris, wo er die Leitung einer Flüchtlingsberatungsstelle der Internationalen Liga für Menschenrechte übernimmt. Außerdem engagiert sich Friedländer weiter für die Sozialdemokratie: Gemeinsam mit Rudolf Breitscheid und anderen gründet er die AWO Paris und nimmt 1935/36 an den Lutetia-Konferenzen zur Gründung einer Volksfront gegen Hitler teil. Ende 1936 folgt Friedländer einem Ruf an die School of Social Service Administration der Universität von Chicago, wo er ein bescheidenes Unterrichtspensum in der Ausbildung von amerikanischen SozialarbeiterInnen übernimmt; 1943 wird er Dozent und später Professor für Social Work an der renommierten School of Social Welfare der Universität von Kalifornien in Berkeley. In zahlreichen Monographien und Sammelbänden befasst er sich ausführlich mit der (Weiter-) Entwicklung des Theorie- und Methodenkanons der Sozialen Arbeit. Seine Bücher „Introduction to Social Welfare“(1955) sowie „Concepts and Methods of Social Work“ (1958) werden Standardwerke der Profession und in zahlreiche Sprachen übersetzt. Im (West-) Deutschland der späten 1960er bis 1980er Jahre gibt es wohl kaum Studierende der Sozialen Arbeit, die die deutsche Übersetzung „Grundbegriffe und Methoden der Sozialarbeit“ nicht kennen. Während der Nachkriegsjahre und insbesondere in seinem Ruhestand ab 1959 ist Friedländer zudem ein gefragter Rat- und Impulsgeber beim (Wieder-) Aufbau der Sozialen Arbeit in Europa, vor allem in Deutschland. Er übernimmt Gastprofessuren in Berlin, Köln sowie Münster und engagiert sich für eine eigenständige, wissenschaftsbasierte Sozialarbeitsprofession. Vor allem der AWO bleibt Friedländer eng verbunden: Bis ins hohe Alter beteiligt er sich mit zahlreichen Reden, Briefen und Fachbeiträgen an der Weiterentwicklung des sozialdemokratischen Wohlfahrtsverbands - trotz der großen räumlichen Entfernung zu seinem kalifornischem Wohnort. Ganz nach Deutschland zurückzukehren ist jedoch wohl nie eine Option für ihn. Am 20. Dezember 1984 stirbt Friedländer in Oakland/Kalifornien.
Text: Martin Biebricher, Zürich, Bild: Felix Meiner Verlag, Hamburg 